\title{
Pattern of some risk factors of cardiovascular diseases and liver enzymes among Iranian seafarers
}

\author{
Fereshteh Baygi ${ }^{1}$, Olaf C Jensen ${ }^{2}$, Mostafa Qorbani ${ }^{3}$, Aliasghar Farshad ${ }^{1}$, Seyed Ali Salehi ${ }^{4}$, \\ Fatemeh Mohammadi ${ }^{5}$, Hamid Asayesh ${ }^{6}$, Farzad Shidfar ${ }^{7 *}$
}

\begin{abstract}
Background: Little information is available on the trend in cardiovascular risk factors and hepatic enzymes in Iranian seafarers. The present study aimed at assessing the pattern of obesity, hypertension, diabetes, elevated serum glutamic oxaloacetate transaminase (SGOT), and serum glutamate pyruvate transaminase (SGPT) in Iranian seafarers during 2010 to 2014.

Methods: Data on cardiovascular risk factors and hepatic enzymes were extracted from seafarers' annual health examination of National Iranian Tanker Company (NITC) of 2010, 2012, and 2014. The repeated measure ANOVA was used to compare continuous variables across 3 years. Categorical data were analyzed using Chi-square test. Over weight was defined as BMI (Body Mass Index) $>25 \mathrm{~kg} / \mathrm{m}^{2}$; obesity was defined as BMI $>=30 \mathrm{~kg} / \mathrm{m}^{2}$; hypertension was defined as systolic blood pressure (SBP) $>140 \mathrm{mmHg}$, and diastolic blood pressure (DBP) $>90 \mathrm{mmHg}$, or a history of antihypertensive drug use. Diabetes (DM) was defined as fasting blood sugar $($ FBS $)>110 \mathrm{mg} / \mathrm{dl}$, or having a history of oral hypoglycemic agents; and elevated SGOT and SGPT were defined as SGOT $>40 \mathrm{U} / \mathrm{L}$ and SGPT $>40 \mathrm{U} / \mathrm{L}$, respectively.

Results: The BMI mean \pm SD values of Iranian seafarers were $24.81 \pm 3.07 \mathrm{~kg} / \mathrm{m}^{2}, 25.51 \pm 2.96 \mathrm{~kg} / \mathrm{m}^{2}$, and $25.96 \pm 3.02 \mathrm{~kg} / \mathrm{m}^{2}$ in 2010 , 2012, and 2014, respectively. A significant difference was observed in BMI over the study period. The mean of systolic and diastolic blood pressure did not significantly increase over time. The SGOT and SGPT means were not significantly different from 2010 to 2014. The prevalence of overweight increased significantly from $46.7 \%$ to $60.9 \%$ over the study period; however, the prevalence of obesity, hypertension, elevated SGOT, and elevated SGPT did not change significantly.

Conclusion: The current survey showed that the obesity problem has increased among Iranian seafarers working on tankers, which is a concerning problem because obesity has negative effects on seafarers' health.
\end{abstract}

Keywords: Seafarer, Cardiovascular, Prevalence, Liver Enzyme, Pattern

Copyright $\odot$ Iran University of Medical Sciences

Cite this article as: Baygi F, Jensen OC, Qorbani M, Farshad AA, Salehi SA, Mohammadi F, Asayesh H, Shidfar F*. Pattern of some risk factors of cardiovascular diseases and liver enzymes among Iranian seafarers. Med J Islam Repub Iran. 2017 (20 Mar); 31:23. https://doi.org/10.18869/mjiri.31.23

\section{Introduction}

Cardiovascular disease (CVD) is the main cause of death in the world (1), and its prevalence has increased in developing countries (2). Overweight, obesity, arterial hypertension, and hypercholesterolemia are some of the main risk factors causing the highest share of cardiovascular disease (3). Statistics show that death due to CVD is $33.7 \%$ in low-and middle-income countries (4). The increase in CVD morbidity and mortality in developing

Corresponding author: Dr Farzad Shidfar, farzadshidfar@yahoo.com

1. Occupational Health Research Center, Iran University of Medical Sciences, Tehran, Iran.

2. Centre of Maritime Health and Society, Institute of Public Health, University of Southern Denmark, Esbjerg, Denmark.

3. Department of Public Health, Alborz University of Medical Sciences, Karaj, Iran

4. National Iranian Tanker Company, Tehran, Iran.

5. Department of Food and Nutrition Policy and Planning Research, National Nutrition and Food Technology Research Institute, Faculty of Nutrition Sciences and Food Technology, Shahid Beheshti University of Medical Sciences, Tehran, Iran.

6. Department of Medical Emergencies, Qom University of Medical Sciences, Qom, Iran.

Department of Nutrition, School of public Health, Iran University of Medical Sciences, Tehran, Iran. countries is associated with increased prevalence of cardiovascular risk factors (5). Several research have studied the prevalence of cardiovascular risk factors and their trends over time in normal population. Data show that about 180 million people have diabetes which will be doubled by the year 2030 in the developing world (6). The prevalence of obesity among adult population was 396 million in 2005, and it is estimated to reach 573 million by

$\uparrow$ What is "already known" in this topic:

The rate of diabetes and obesity is increasing exponentially. The prevalence of cardiovascular risk factors have increased during the recent years among the seafarers in various countries.

$\rightarrow$ What this article adds:

The obesity has an increasing among Iranian seafarers working on tankers during 2010-2014. This is a main concern because obesity has negative effects on the health condition of the seafarers. 
Table 1. Mean \pm SD of the cardiovascular risk factors and hepatic enzymes on the participants from 2010 to 2014

\begin{tabular}{lllll}
\hline & & Year, Mean \pm SD & \\
\hline Risk Factors & 2010 & 2012 & 2014 & P-Trend \\
BMI & $24.81 \pm 3.07$ & $25.51 \pm 2.96$ & $25.96 \pm 3.02$ & $<0.001$ \\
Systolic blood pressure & $119.46 \pm 13.22$ & $119.14 \pm 15.10$ & $122.38 \pm 14.41$ & NS \\
Diastolic blood pressure & $75.94 \pm 8.74$ & $74.95 \pm 9.99$ & $78.89 \pm 9.49$ & NS \\
Fasting blood glucose & $96.24 \pm 13.82$ & $95.68 \pm 13.40$ & $95.53 \pm 18.13$ & NS \\
SGOT & $23.76 \pm 9.27$ & $21.52 \pm 7.93$ & $25.57 \pm 9.21$ & NS \\
SGPT & $32.29 \pm 18.55$ & $28.47 \pm 13.92$ & $32.20 \pm 16.02$ & NS \\
\hline
\end{tabular}

2030 (7).

In 2008 , a national study in Iran indicated that $7.7 \%$ of Iranian adults had diabetes, and $16.8 \%$ had impaired fasting glucose (8). Also, the estimated total number of Iranian obese males and females in 2005 was $42.8 \%$ and $57 \%$, respectively (9). Based on the current studies on Iranian seafarers, the prevalence of MetS (Metabolic Syndrome) was $15 \%$, and a large proportion of them had abdominal obesity (10). By 2015, these numbers are projected to be $54 \%$ and $74 \%$, respectively (11). Previous studies revealed that the prevalence of hypertension among Iranian adults was $25.2 \%$ in 2005 (12); this figure reached to $26.6 \%$ in 2007 (13). Moreover, the majority of the patients with nonalcoholic fatty liver disease (NAFLD), who are obese, suffer abdominal obesity, Type 2 diabetes, and other cardiovascular risk factors (14). Results of the National Health and Nutrition Examination Survey (NHANES) revealed that about $70 \%$ of the elevated aminotransferase activity was significantly associated with higher body mass index, waist circumference, triglycerides, fasting insulin, and lower high density lipoprotein (HDL) cholesterol (15).

Seafaring is a crucial job in Iran, and the literature review shows that the prevalence of cardiovascular risk factors have increased during the recent years among the seafarers (16). Moreover, the prevalence of overweight, hypertension, and hypercholesterolemia increased during 1990s and 2000s among seafarers form various countries (16). Data revealed that the prevalence of obesity among Turkish seafarers has increased, and the highest level of BMI was observed among seafarers aged 50 to 60 years (17). Little is known about the trend in cardiovascular risk factors and hepatic enzymes in Iranian seafarers. Accordingly, the present study aimed at assessing the pattern of obesity, hypertension, diabetes, elevated SGOT, and SGPT in Iranian seafarers during 2010 to 2014.

\section{Methods}

\section{Data}

A retrospective cohort study was conducted, examining 500 Iranian male seafarers of NITC, who referred to health units for annual health examination to assess some patterns of risk factors of cardiovascular disease and liver enzymes. From 500 participants, 169 (33\%) seafarers had at least 6 months of sea services and complete medicaldemographic data in 2010, 2012, and 2014.

Data on cardiovascular risk factors and hepatic enzymes were derived from seafarers' annual health examination of NITC of 2010, 2012, and 2014. The health examination data included age, height, weight, FBS, SGOT and SGPT, systolic, and diastolic blood pressure.

Measurement

Anthropometric parameters including height, weight, and blood pressure were measured according to standardized protocols. Weight was measured in light clothing without shoes using an electronic scale (Seca, 707; range 0.1-150 kg); height was measured without shoes using a tape meter, stadiometer. Body mass index (BMI) was calculated as weight $(\mathrm{kg}) /$ height $^{2}\left(\mathrm{~m}^{2}\right)$. Systolic and diastolic blood pressure were measured twice after 15 minutes rest and averaged in seated position, applying a standard mercury sphygmomanometer.

FBS (after 12-14 hours fasting), SGOT, and SGPT were tested using the relevant kits obtained from the Pars Azmoon Company, Iran, by an automatic analytical machine (BT3000, Italy).

Overweight was defined as BMI $>25 \mathrm{~kg} / \mathrm{m}^{2}$; obesity was defined as BMI $>=30 \mathrm{~kg} / \mathrm{m}^{2}$. High systole and high diastole were defined as systolic blood pressure (SBP) $>140$ $\mathrm{mmHg}$ and diastolic blood pressure (DBP) $>90 \mathrm{mmHg}$, respectively. Hypertension was defined as systolic blood pressure $(\mathrm{SBP})>140 \mathrm{mmHg}$ and diastolic blood pressure (DBP) $>90 \mathrm{mmHg}$ or a history of antihypertensive drug use (18). Diabetes was defined as fasting blood glucose $>$ $110 \mathrm{mg} / \mathrm{dL}$, or having a history of oral hypoglycemic agents (18). Elevated SGOT and SGPT were defined as SGOT $>40 \mathrm{U} / \mathrm{L}$ and SGPT $>40 \mathrm{U} / \mathrm{L}$, respectively (19).

Ethical Considerations

This study was proposed and approved by the Ethics-inResearch Commission of Iran University of Medical Sciences. Also, permission was achieved from NITC to use Iranian seafarer information.

\section{Statistical Analysis}

The data were analyzed using SPSS16. Continuous variables were reported in mean and standard deviation (SD). The repeated measure ANOVA was used to compare continuous variables across 3 years. Categorical data were analyzed using Chi-square test. The significant level was set at $\mathrm{p}<0.05$.

\section{Results}

The mean (SD) age of Iranian seafarers was 42.8 (10.4) years, and the mean (SD) job history was 16.7 (10.60) years. A total of $89(52.7 \%)$ and $80(47.3 \%)$ of the participants had diploma and academic degree, respectively; 77 $(45.6 \%)$ did shift work.

Table 1 demonstrates the mean of BMI, FBS, SBP, DBP, and hepatic enzymes among participants in 3 intervals. The BMI mean of the participants significantly increased from 2010 to $2014(\mathrm{p}<0.001)$. In 2010, the mean 
Table 2. Prevalence of cardiovascular risk factors and hepatic enzymes on the participants from 2010 to 2014

\begin{tabular}{|c|c|c|c|c|c|}
\hline \multicolumn{6}{|c|}{ Year, Prevalence, $\%$} \\
\hline Risk factors & 2010 & 2012 & 2014 & Relative Change From 2010 to $2014, \%$ & $P$ value \\
\hline Overweight & $79(46.7)$ & $99(58.6)$ & $103(60.9)$ & 30.37 & $<0.01$ \\
\hline High diastole & $20(11.8)$ & $35(20.7)$ & $24(14.2)$ & 20 & NS \\
\hline Hypertension & $26(15.4)$ & $41(24.3)$ & $40(23.7)$ & 53.84 & NS \\
\hline Diabetes & $37(21.9)$ & $33(19.5)$ & $49(29.0)$ & 32.43 & NS \\
\hline Overweight\& Hypertension & $21(12.4)$ & $26(15.4)$ & $30(17.8)$ & 42.85 & NS \\
\hline Overweight\& Diabetes & $23(13.6)$ & $16(9.5)$ & $28(16.6)$ & 21.73 & NS \\
\hline Hypertension\& Diabetes & $10(5.9)$ & $8(4.7)$ & $10(5.9)$ & 0 & NS \\
\hline Hypertension\& Diabetes\& Overweight & $27(16.9)$ & $35(21.3)$ & $38(23.9)$ & 40.74 & NS \\
\hline Elevated SGOT\& Elevated SGPT & $10(5.9)$ & $4(2.4)$ & $7(4.1)$ & -30.0 & NS \\
\hline
\end{tabular}

(SD) values of SBP and DBP were $119.46(13.22) \mathrm{mmHg}$ and 75.94 (8.74) $\mathrm{mmHg}$, respectively. In 2014, these mean values were 122.38 (14.41) $\mathrm{mmHg}$ and 78.89 (9.49) $\mathrm{mmHg}$, respectively; however, this increase was not statistically significant $(\mathrm{p}=0.062)$. Although the FBS mean decreased over the study period, it was not statistically significant $(p=0.22)$. The mean values of SGOT and SGPT did not change significantly among participants from 2010 to 2014 .

The prevalence of cardiovascular risk factors and hepatic enzyme among Iranian seafarers are presented in Table 2. The prevalence of overweight increased significantly from $46.7 \%$ to $60.9 \%$ over the study period. Although the prevalence of obesity enhanced from $4.1 \%$ to $8.9 \%$, it was

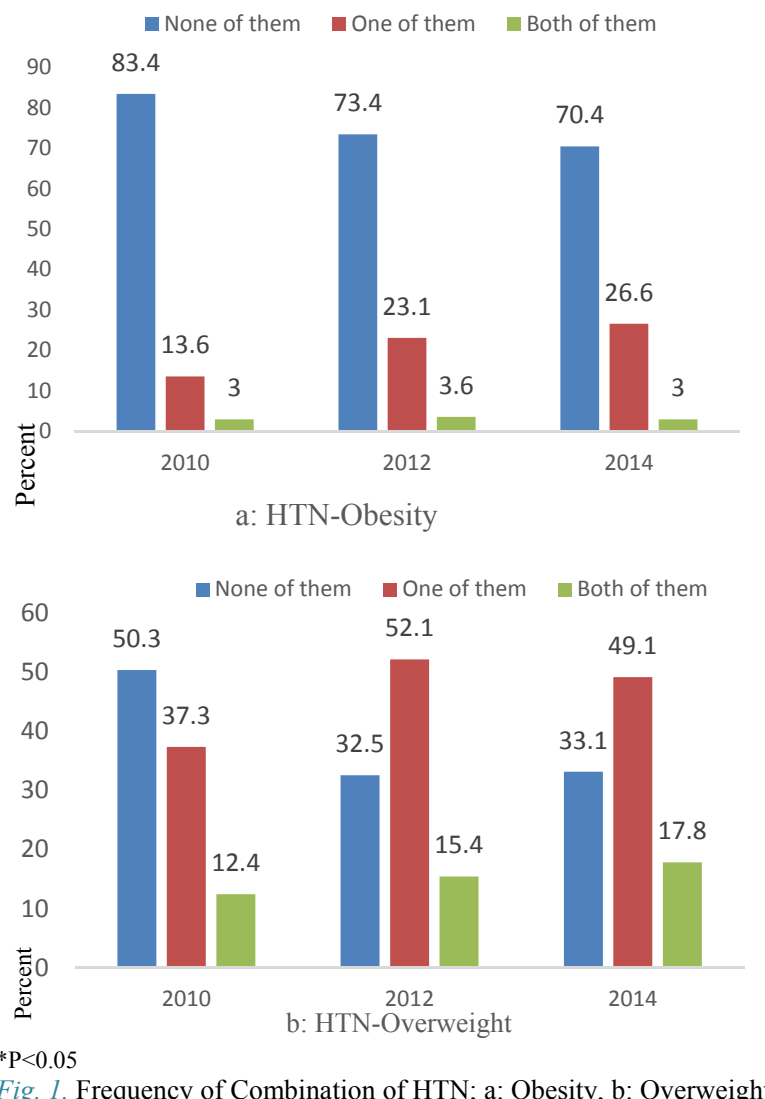

not statistically significant. The rate of high SBP, high DBP, HTN, and diabetes increased from 2010 to 2014; however, the changes were not significant. The prevalence of elevated SGOT and SGPT were $6.5 \%$ and $25.4 \%$ in 2010 , respectively; this prevalence was $5.9 \%$ and $21.3 \%$ in 2014, respectively, indicating no significant change between 2010 and 2014 prevalence values.

Figures 1-3 demonstrates the frequency of different combinations of cardiovascular risk factors from 2010 to 2014. The prevalence of having "HTN and obesity" did not change significantly over time, but the frequency of having "HTN and overweight" significantly increased from $12.4 \%$ to $17.8 \%$. The frequency of combination of DM-overweight significantly increased from 2010 to 2014. Also, the prevalence of having diabetes-overweightHTN among Iranian seafarers increased significantly from $5.3 \%$ to $5.9 \%$ between 2010 until 2014 ( $\mathrm{p}<0.05)$.

\section{Discussion}

The current study provides primary data on the increasing trend of overweight in Iranian seafarers' population over the study period. The prevalence of hypertension, diabetes, elevated SGOT, and SGPT increased nonsignificantly from 2010 to 2014. Studies have found that the risk factors of non-communicable diseases' trend have been increasing in both developing and developed countries (20-22). The prevalence of obesity among American adults increased from $13 \%$ to $32 \%$ between 1960 s and $2004(23,24)$. Similar increasing trend of diabetes is reported in adults' population in the USA (25). The prevalence of obesity in Europe has doubled over the past 10 to 15 years (26). In developing countries, the increasing prevalence of diabetes is estimated to increase from 3.3\% to $4.9 \%$ from 1995 to 2025 (27). A similar increase in obesity prevalence has been observed in developing countries (20); in Kuwait and Oman, the obesity prevalence rate has risen in recent years. The national prevalence of obesity in Kuwait increased from $15 \%$ to $28 \%$ from 1980 to 1994 (28), and in Oman, it increased from $10.5 \%$ to $16.7 \%$ from 1991 to 2000 (29). Recent studies have revealed that cardiovascular diseases risk factors have also increased in Iranian adults' population (3, 13, 30, 31). Data from the National Survey of Risk Factors of NonCommunicable Diseases (SuRFNCD) showed that the 
prevalence of obesity increased from $13.6 \%$ in 1999 to $19.6 \%$ in 2005 and to $22.3 \%$ in 2007 among Iranian adults. During these years, the national prevalence of overweight was $32.2 \%, 35.8 \%$, and $36.3 \%$, respectively; ie, $4.1 \%$ increase in 8 years (3). According to SuRFNCD, the rate of diagnosed diabetes was $2.5 \%, 4.0 \%$, and $4.6 \%$ in 1999, 2005, and 2007, respectively; ie, during 8 years, the prevalence of diabetes rose more than 1.8 fold among Iranian adults (31). In 2005, the national prevalence of hypertension was $25.2 \%$; this number was $26.6 \%(1.4 \%$ increase in 2 years) in 2007 (13). Other studies presented alarming increases in the prevalence of overweight, obesity, and abdominal obesity in different regions of Iran (30, $32,33)$. Possible reasons which can be accounted for in-
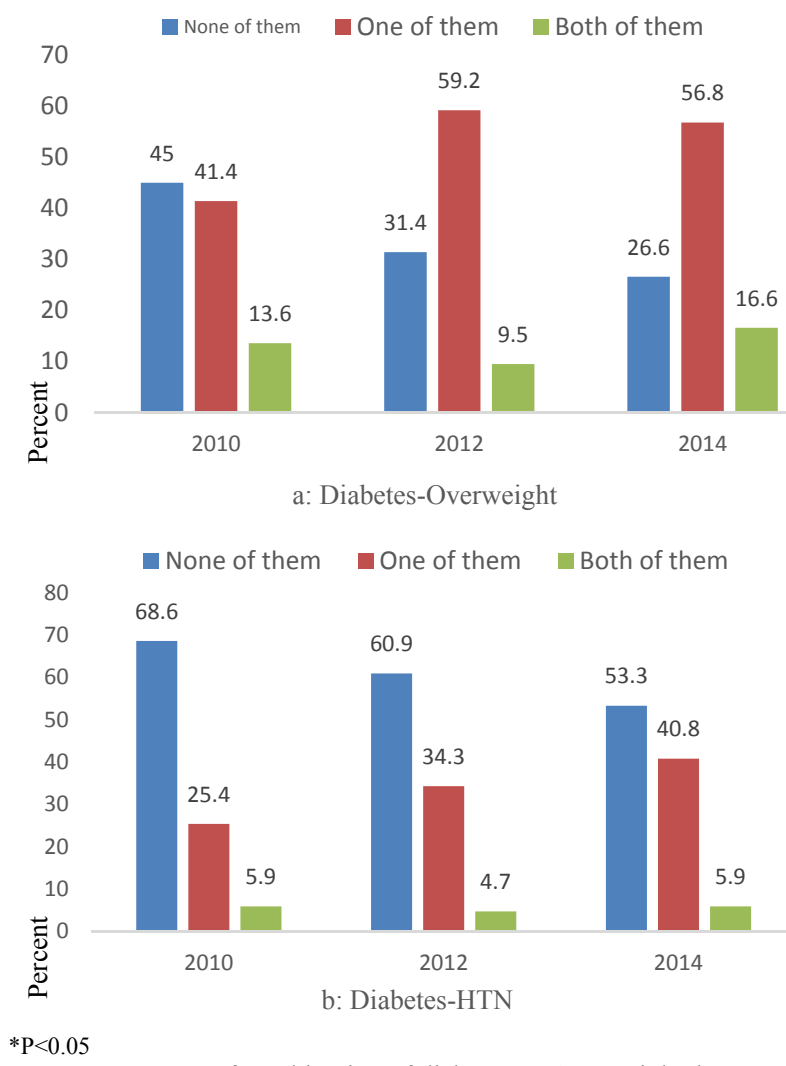

Fig. 2. Frequency of combination of diabetes. a: Overweight, b: HTN

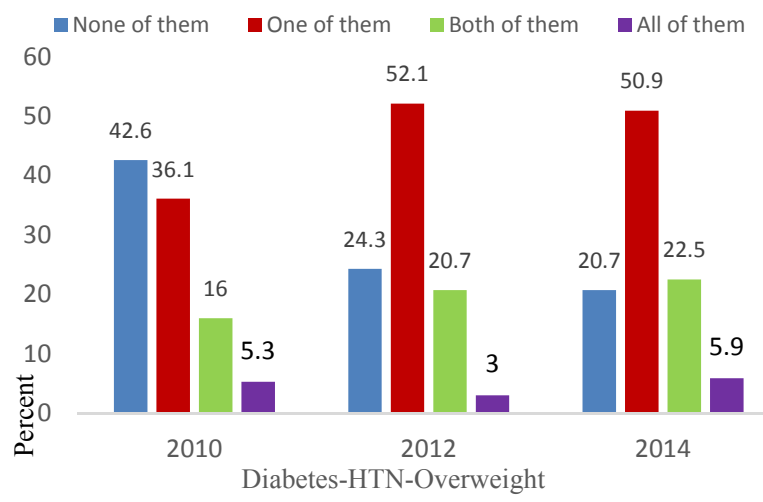

$* \mathrm{P}<0.001$

Fig. 3. Frequency of combination of diabetes and HTN and overweight crease in the prevalence of non-communicable diseases are improper dietary habits, inactivity, speedy urbanization, and imparity in health care (34).

The prevalence of cardiovascular risk factors are high among seafarers, which might be due to their different lifestyle (16). In the current study, the overweight trend increased significantly among seafarers by $14.2 \%$ from 2010 to 2014. The mean of BMI significantly increased among Iranian seafarers over time. The present findings are consistent with other studies $(16,17,35)$. A review on the prevalence of cardiovascular risk factors among seafarers during 1990s and 2000s showed that the prevalence of overweight was $47.1 \%$ in 1990 s and $64.1 \%$ in 2000 s; and the prevalence of overweight increased significantly over time (16). Findings of Nas revealed that the mean of BMI among Turkish seafarers significantly raised from 2009 to 2012, and when the Turkish seafarers got older, their BMI values increased gradually (17). A survey was performed among Danish seafarers to find the trend of BMI from 2001/2002 to 2010, showing that the overweight prevalence was $64 \%$ in $2001 / 2002$ and increased to $70.5 \%$ in 2010; and the relative risk of being overweight in 2010 was 1.08 compared to 2001/2002 (35). Published data show that the prevalence of high blood pressure significantly increased from $14.8 \%$ in 1990 s to $42.1 \%$ in 2000s among seafarers (16), which is inconsistent with the present study. In our study, the mean of SBP and DBP did not increase significantly, and the trend of high systole, high diastole, and hypertension rose nonsignificantly among Iranian seafarers from 2010 to 2014. The findings revealed that the mean of fasting blood glucose did not change significantly over time, and the trend of diabetes did not increase significantly. The results are consistent with Pougnet et al.'s study (16), in which the prevalence of glycemic abnormalities or diabetes increased nonsignificantly from $3.9 \%$ to $4.0 \%$ during 1990 s and 2000 s. Documentaries show that factors such as inactivity, lack of sleeping, stress of work, unhealthy diet, and long job duration contribute to increase in cardiovascular risk factors among seafarers (36).

In our study, the mean of hepatic enzymes increased non-significantly from 2010 to 2014 among Iranian seafarers, hich might have been due to the short duration of the study or small sample size. Elevated level of SGPT is the main liver abnormality in NAFLD and nonalcoholic steatohepatitis (NASH). Statistics showed that the NAFLD prevalence was $25 \%$ among American adults (37). Previous studies have revealed significant associations between components of metabolic syndrome and NAFLD and NASH (38). The prevalence of elevated SGPT among Iranian population is $4.3 \%$, suggesting that the rate of NAFLD/NASH and related complications are expected to rise among Iranian population in the future (39). Recent evidences indicate that NAFLD is the main common reason of liver disease in Iran (40).

The main strength of the study was that it was the first study to report the pattern of cardiovascular risk factors and liver enzymes among Iranian seafarers working on tankers. The study had a number of limitations: Nutritional habits and physical activity were not considered simul- 
taneously in the study, moreover, the study was conducted in a short-term; and in this regard small sample size might have been the main reason for non-significant results of the current survey. Thus, the results may not be appropriately generalized.

\section{Conclusions}

The current survey showed that the obesity problem has increased among Iranian seafarers working on tankers in the recent years, which is a main concern because obesity has negative effects on the health condition of the seafarers. Longitudinal studies on seafarers are needed to investigate the trend of cardiovascular risk factors and other risk factors of this occupation.

\section{Acknowledgments}

The study data were derived from the $\mathrm{PhD}$ thesis of Ms. Fereshteh Baygi, a student of the Occupational Health Research Center of Iran University of Medical Sciences. The authors gratefully acknowledge the financial support of Iran University of Medical Sciences (Grant No. 25800). The authors would like to thank the manager and participants of National Iranian Tanker Company for their contribution.

Conflict of Interests: The authors declare no competing interests.

\section{References}

1. Fuster V, Voute J. MDGs: chronic diseases are not on the agenda. Lancet. 2005;366(9496):1512-4.

2. Gaziano TA. Cardiovascular disease in the developing world and its cost-effective management. Circulation. 2005;112(23):3547-53.

3. Esteghamati A, Khalilzadeh O, Mohammad K, Meysamie A, Rashidi A, Kamgar M, et al. Secular trends of obesity in Iran between 1999 and 2007: National Surveys of Risk Factors of Non-communicable Diseases. Metabolic syndrome and related disorders. 2010;8(3):20913.

4. Gaziano TA, Bitton A, Anand S, Abrahams-Gessel S, Murphy A. Growing epidemic of coronary heart disease in low-and middleincome countries. Current problems in cardiology. 2010;35(2):72115 .

5. Reddy KS. Cardiovascular disease in non-Western countries. New England Journal of Medicine. 2004:2438-510.

6. Hossain P, Kawar B, El Nahas M. Obesity and diabetes in the developing world - a growing challenge. New England Journal of Medicine. 2007;356(3):213-5.

7. Kelly T, Yang W, Chen C-S, Reynolds K, He J. Global burden of obesity in 2005 and projections to 2030 . International journal of obesity. 2008;32(9):1431-7.

8. Esteghamati A, Gouya MM, Abbasi M, Delavari A, Alikhani S, Alaedini F, et al. Prevalence of Diabetes and Impaired Fasting Glucose in the Adult Population of Iran: National Survey of Risk Factors for Non-Communicable Diseases of Iran. Diabetes Care. 2008;31(1):96-8.

9. Janghorbani M, Amini M, Willett WC, Gouya MM, Delavari A, Alikhani S, et al. First nationwide survey of prevalence of overweight, underweight, and abdominal obesity in Iranian adults. Obesity. 2007;15(11):2797-808.

10. Baygi F, Jensen O, Qorbani M, Farshad A, Salehi S, Mohammadi F, et al. Prevalence and Associated Factors of Cardio-Metabolic Risk Factors in Iranian Seafarers. Int Marit Health. 2016;67(2):59-65.

11. Chronic deaseases are the major cause of death and disability worldwide: World Health Organization; [updated Cited 2008 Aug 12]. Available from: [http://www.who.int/chp/chronic_disease report/media/Factsheet1.pdf].

12. Esteghamati A, Abbasi M, Alikhani S, Gouya MM, Delavari A,
Shishehbor MH, et al. Prevalence, awareness, treatment, and risk factors associated with hypertension in the Iranian population: the national survey of risk factors for noncommunicable diseases of Iran. Am J Hypertens. 2008;21(6):620-6.

13. Esteghamati A, Meysamie A, Khalilzadeh O, Rashidi A, Haghazali $\mathrm{M}$, Asgari F, et al. Third national Surveillance of Risk Factors of Non-Communicable Diseases (SuRFNCD-2007) in Iran: methods and results on prevalence of diabetes, hypertension, obesity, central obesity, and dyslipidemia. BMC public health. 2009;9(1):167.

14. Targher G, Arcaro G. Non-alcoholic fatty liver disease and increased risk of cardiovascular disease. Atherosclerosis. 2007;191(2):235-40

15. Schindhelm RK, Diamant M, Dekker JM, Tushuizen ME, Teerlink $\mathrm{T}$, Heine RJ. Alanine aminotransferase as a marker of non-alcoholic fatty liver disease in relation to type 2 diabetes mellitus and cardiovascular disease. Diabetes/metabolism research and reviews. 2006;22(6):437-43.

16. Pougnet R, Pougnet L, Loddé BL, Canals-Pol ML, Jegaden D, Lucas D, et al. Cardiovascular risk factors in seamen and fishermen: review of literature. International maritime health. 2013;64(3):107-13.

17. Nas S, Fișkın R. A research on obesity among Turkish seafarers. International maritime health. 2014;65(4):187-91.

18. S A, H K, MR M, B L, MH F, H A. Cut-off points of waist circumference and body mass index for detecting diabetes, hypercholesterolemia and hypertension according to National Non-Communicable Disease Risk Factors Surveillance in Iran. Arch Med Sci. 2011;8(4):614-21.

19. Rogha M, Najafi N, Azari A, Kaji M, Pourmoghaddas Z, Rajabi F et al. Non-alcoholic Steatohepatitis in a Sample of Iranian Adult Population: Age is a Risk Factor. Int J Prev Med. 2011;2(1):24-7.

20. Finucane MM, Stevens GA, Cowan MJ, Danaei G, Lin JK, Paciorek $\mathrm{CJ}$, et al. National, regional, and global trends in body-mass index since 1980: systematic analysis of health examination surveys and epidemiological studies with 960 country-years and $9 \cdot 1$ million participants. The Lancet. 2011;377(9765):557-67.

21. Kearney PM, Whelton M, Reynolds K, Muntner P, Whelton PK, He J. Global burden of hypertension: analysis of worldwide data. The Lancet. 2005;365(9455):217-23.

22. Danaei G, Finucane MM, Lu Y, Singh GM, Cowan MJ, Paciorek $\mathrm{CJ}$, et al. National, regional, and global trends in fasting plasma glucose and diabetes prevalence since 1980: systematic analysis of health examination surveys and epidemiological studies with 370 country-years and 2. 7 million participants. The Lancet. 2011;378(9785):31-40.

23. Wang Y, Beydoun MA. The obesity epidemic in the United States-gender, age, socioeconomic, racial/ethnic, and geographic characteristics: a systematic review and meta-regression analysis. Epidemiologic reviews. 2007;29(1):6-28.

24. Ogden CL, Yanovski SZ, Carroll MD, Flegal KM. The epidemiology of obesity. Gastroenterology. 2007;132(6):2087-102.

25. Cowie CC, Rust KF, Ford ES, Eberhardt MS, Byrd-Holt DD, Li C, et al. Full accounting of diabetes and pre-diabetes in the US population in 1988-1994 and 2005-2006. Diabetes Care. 2009;32(2):28794.

26. Berghöfer A, Pischon T, Reinhold T, Apovian CM, Sharma AM, Willich SN. Obesity prevalence from a European perspective: a systematic review. BMC public health. 2008;8(1):200.

27. King H, Aubert RE, Herman WH. Global burden of diabetes, 1995 2025: prevalence, numerical estimates, and projections. Diabetes Care. 1998;21(9):1414-31.

28. Al-Isa A. Changes in body mass index (BMI) and prevalence of obesity among Kuwaitis 1980-1994. International journal of obesity and related metabolic disorders: journal of the International Association for the Study of Obesity. 1997;21(12):1093-9.

29. Al-Lawati JA, Jousilahti PJ. Prevalence and 10-year secular trend of obesity in Oman. Saudi medical journal. 2004;25(3):346-51.

30. Azizi F, Azadbakht L, Mirmiran P. Trends in overweight, obesity and central fat accumulation among Tehranian adults between 19981999 and 2001-2002: Tehran lipid and glucose study. Annals of nutrition and metabolism. 2005;49(1):3-8.

31. Esteghamati A, Ashraf H, Khalilzadeh O, Rshidi A, Mohammad K, Asgari F, et al. Trends of diabetes according to body mass index levels in Iran: results of the national Surveys of Risk Factors of NonCommunicable Diseases (1999-2007). Diabetic Medicine. 2010;27(11):1233-40. 
32. Hosseinpanah F, Barzin M, Eskandary PS, Mirmiran P, Azizi F. Trends of obesity and abdominal obesity in Tehranian adults: a cohort study. BMC public health. 2009;9(1):426.

33. Veghari G, Sedaghat M, Maghsodlo S, Banihashem S, Moharloei P, Angizeh A, et al. Obesity trends of adults in northern Iran (20062010). 2013

34. Galal O. Nutrition-related health patterns in the Middle East. Asia Pacific journal of clinical nutrition. 2002;12(3):337-43.

35. Hansen HL, Hjarnø L, Jepsen JR. Obesity continues to be a major health risk for Danish seafarers and fishermen. International maritime health. 2011;62(2):98.

36. Oldenburg M. Risk of cardiovascular diseases in seafarers. International maritime health. 2014;65(2):53-7.

37. Green RM. NASH - hepatic metabolism and not simply the metabolic syndrome. Hepatology. 2003;38(1):14-7.

38. Donati G, Stagni B, Piscaglia F, Venturoli N, Morselli-Labate A, Rasciti L, et al. Increased prevalence of fatty liver in arterial hypertensive patients with normal liver enzymes: role of insulin resistance. Gut. 2004;53(7):1020-3.

39. Sohrabpour AA, Rezvan H, Amini-Kafiabad S, Dayhim MR, Merat S, Pourshams A. Prevalence of Nonalcoholic Steatohepatitis in Iran: A Population based Study. Middle East Journal of Digestive Diseases. 2010;2(1):14-9.

40. Jamali R, Khonsari M, Merat S, Khoshnia M, Jafari E, Bahram Kalhori A, et al. Persistent alanine aminotransferase elevation among the general Iranian population: prevalence and causes. World J Gastroenterol. 2008;14(18):2867-71. 